intrinsic defect, as in coeliac disease and a fair proportion of adult cases, but that in others it may be secondary to some other disease. The list of causative diseases is already long and probably others will be added. The implication to be drawn from the patients in Group III is that the primary disease may either be well established years before the mucosal change or that the malabsorption and mucosal abnormality present shortly beforehand. With this in mind it is suggested that all patients with a short history of malabsorption should be suspected of an underlying disease which may be excluded only by observation over a period of time.

The terminology of this condition has never been satisfactory, and the label "idiopathic steatorrhoea" has long been challenged. We would suggest the substitution of coeliac syndrome, which may be primary or secondary, as being accurate and euphonious, until more definite knowledge is available.

\section{Summary}

Fifty patients with a flat small-intestinal mucosa have been reviewed. Eight $(16 \%)$ had coeliac disease and $24(48 \%)$ had no disease other than a malabsorption state. The remaining $18(36 \%)$ had some other disease which either antedated the onset of malabsorption by many years or succeeded it by a relatively short interval. It is suggested that in this last group the flat mucosa was a complication of the associated disease. If this explanation is correct then the finding of a flat jejunal mucosa on biopsy can no longer be regarded as diagnostic of idiopathic steatorrhoea.

\section{REFERENCES}

Astaldi, G., Grandini, U., Poggi, C., and Strosselli, E. (1964). Amer. F. dig. Dis., 9, 237.

Creamer, B. (1964a). Brit. med. f., 2, 1373.

(1964b). Ibid., 2, 1435.

Eakins, D., Fulton, 'T., and Hadden, D. R. (1964). Gut, 5, 315.

Ellenberg, M., and Bookman, J. J. (1960). Diabetes, 9, 14.

Gough, K. R., Read, A. E., and Naish, J. M. (1962). Gut, 3, 232.

Gough, K. R., Read, A. E., and Naish,
Goulston, K. J. (1964). Ibid., 5, 490.

Goulston, K. J. (1964). Ibid., 5, 490.
Hindle, W., and Creamer, B.'(1965). Brit. med. F., 2, 458.
Holmes, R., Hourihane, D. O'B., and Booth, C. C.'(1961a). Lancet, 1, 81 .

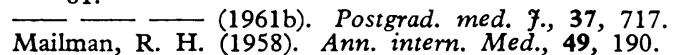

Paulley, J. W. (1954). Brit. med. F., 2, 1318.

Salem, S. N., Truelove, S. C., and Richards, W. C. D. (1964). Ibid.,

1, 394. (1956). Lancet, 1, 85.
Shiner, M.

(1960). Gut, 1, 48.

- and Doniach, I. (1960). Gastroenterology, 38, 419.

Vinnik, I. E., Kern, F., jun., and Struthers, J. E., jun. (1962). Ibid., 43,

Wells, G. C. (1962). Brit. med. f., 2, 937.

\title{
Clinical Picture Accompanying a Flat Small-intestinal Mucosa
}

\author{
W. HINDLE,* M.D., B.SC., M.R.C.P. ; B. CREAMER,* M.D., M.R.C.P.
}

Brit. med. F., 1965, 2, 458-459

The diagnostic significance of a flat jejunal mucosa and its relation to other diseases has been discussed in a previous paper (Hindle and Creamer, 1965). It was suggested that those patients in whom there was no associated disease should be regarded as having a primary coeliac syndrome, whereas in those in whom certain other disease was present the coeliac syndrome should be regarded as a secondary manifestation. In this article the clinical and investigative findings in the same 50 patients with flat jejunal mucosa are described, and an attempt is made to see if primary and secondary coeliac syndromes can be distinguished on these grounds.

\section{Cases and Investigations}

The case records of 50 patients with an unequivocally flat jejunal mucosa were examined. There were 26 males and 24 females, their ages ranging from 15 to 74 years. In 49 cases the biopsy specimen was obtained perorally, and in one case it was taken at operation. All patients were fully investigated at the time of biopsy. The range of investigations used is listed below, although not every patient had all the tests performed.

Haematology.-Full blood count, E.S.R., serum iron, serum folate, Figlu test, serum vitamin $\mathrm{B}_{12}$, Schilling test, and sternal-marrow examination.

Biochemistry.-Five-day faecal fat excretion, xylose excretion, glucose-tolerance curves, serum potassium, serum calcium, serum phosphorus, alkaline phosphatase, and plasma proteins.

Radiology.-Small-bowel meal.

Histology.-The biopsy specimens were examined under the dissecting microscope. They were accurately orientated and after section were examined by conventional microscopy.

* St. Thomas's Hospital, London.

\section{Results}

For the purpose of analysis patients with coeliac disease have been grouped with those who developed symptoms of malabsorption in adult life but had no evidence of any other disease (primary coeliac syndrome). There were 32 patients in this group (16 males and 16 females); 18 (10 males and 8 females) had a secondary coeliac syndrome.

Fig. 1 contrasts the incidence of various symptoms in the patients with primary and secondary coeliac syndromes. It is clear that in the two groups there is no difference in the frequency of occurrence of diarrhoea, loss of weight, or reduction in appetite. Patients with a secondary coeliac syndrome complained of abdominal pain and oedema almost twice as often as did those with a primary coeliac syndrome. However, the number of patients with these complaints was small and the difference between the two groups may not be signifi-

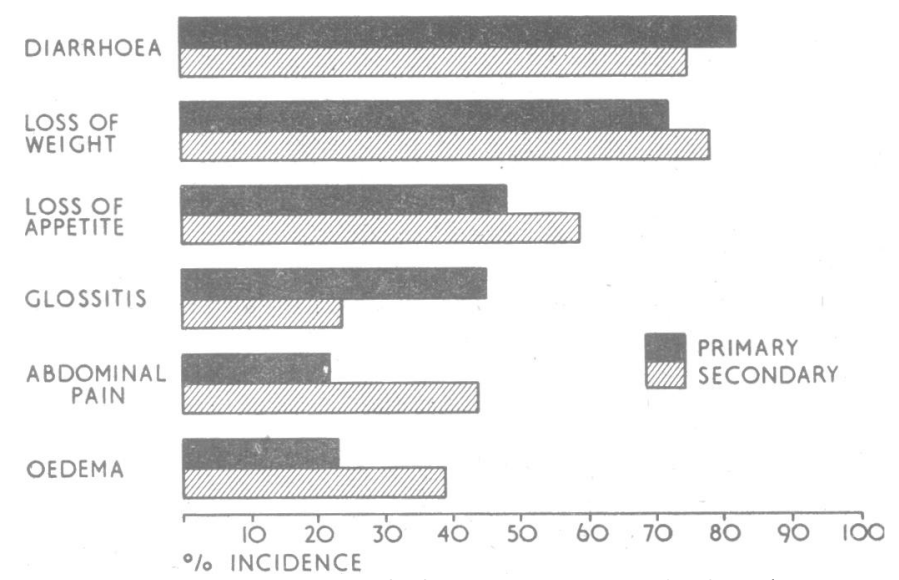

FIG. 1.-Diagram showing the incidence of symptoms in the primary and secondary coeliac syndromes. 
cant. Soreness of the tongue was more frequent $(45 \%)$ in the primary group than in the secondary group (24\%), but again the number of patients involved was small.

The results of some of the haematological investigations are shown in Fig. 2. Wide variations in the haemoglobin, E.S.R., serum vitamin $\mathrm{B}_{12}$, and Schilling test were found in both primary and secondary coeliac syndromes. The mean values for the two groups were similar. The mean corpuscular
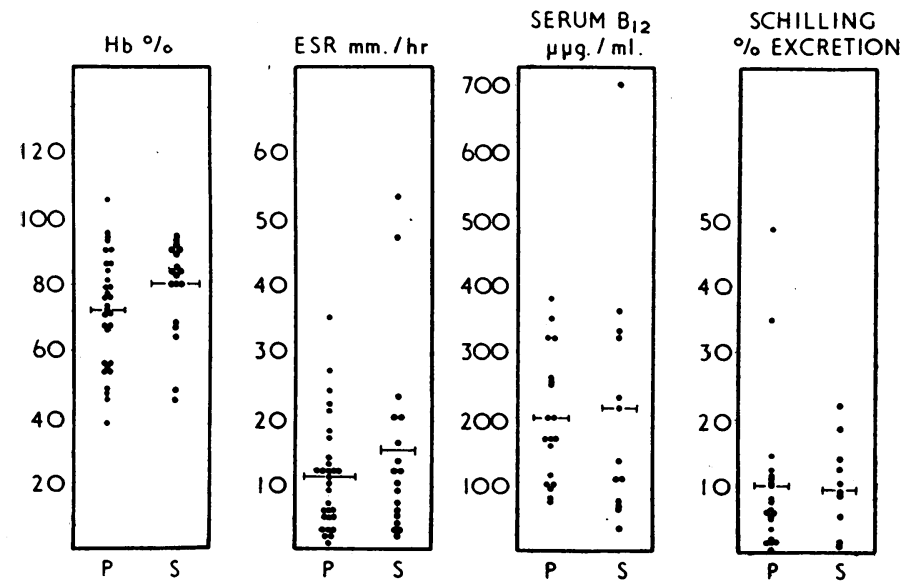

Fig. 2.-Diagram of haematological data in the primary and secondary coeliac syndromes. $\mathrm{P}=$ primary $; \mathrm{S}=$ secondary. The means are indicated by a bar.
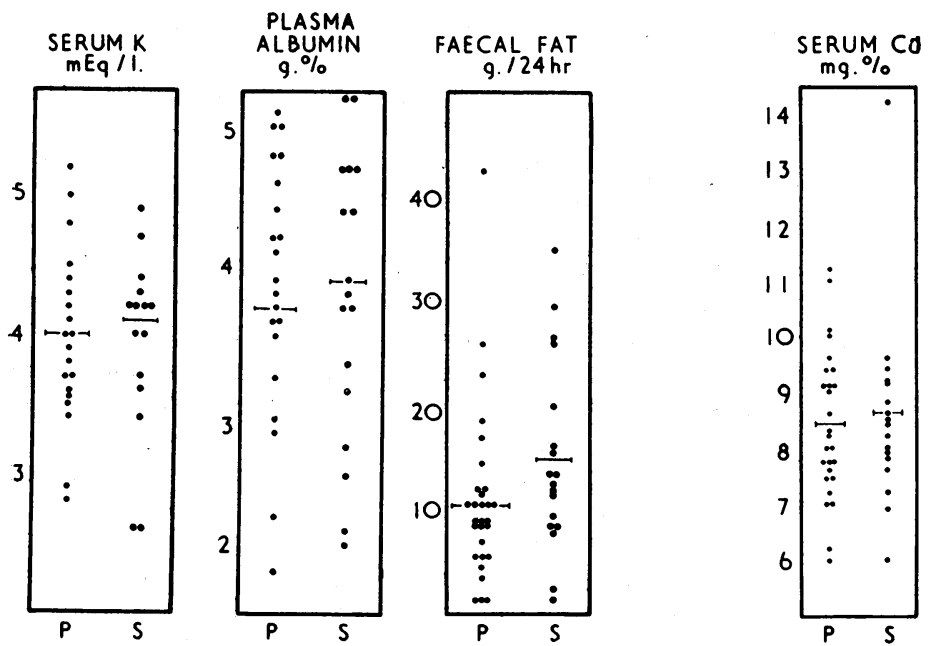

FIG. 3.-Diagram of biochemical data in the primary and secondary coeliac
secondary. The means are indicated by a bar.

haemoglobin concentration was $30 \%$ in the primary group and $31 \%$ in the secondary group. There were insufficient records of the serum iron, serum folate, and Figlu test to make adequate comparisons, but no obvious difference was noted between the two groups. All of the 17 patients with a primary coeliac syndrome in whom the sternal marrow was examined showed megaloblastic changes, and similar changes were seen in seven out of nine patients with a secondary coeliac syndrome.

Biochemical data are shown in Fig. 3. Again there was a wide variation in the values obtained for faecal fats, serum calcium, phosphorus, alkaline phosphatase, potassium, and plasma albumin. No distinction could be made between the groups with a primary or a secondary coeliac syndrome, and the mean values for the two groups are very similar. Neither xylose-excretion nor glucose-tolerance curves showed any difference between the two groups.

Review of the small-bowel $x$-ray films of both groups of patients showed that the typical deficiency pattern was present in some degree in almost all the cases examined.
The histological and dissecting-microscopical appearances of the biopsy specimens were similar in all patients and there was nothing which enabled us to differentiate between the two groups.

The response of the patients in the two groups to a glutenfree diet was also similar. In the primary coeliac group 25 out of 32 cases were placed on a gluten-free regimen; $16(64 \%)$ had a good response and $3(12 \%)$ had a fair response to the diet, making a total of $19(76 \%)$ in whom the diet was of benefit. Of the 18 patients with a secondary coeliac syndrome 12 were placed on a gluten-free diet. In $10(83 \%)$ of these patients there was a good response to the diet. Two (12\%) of the patients also had excision of benign jejunal strictures, so that it is uncertain whether this or the gluten-free diet was responsible for the improvement of their symptoms. It is clear, however, that similar proportions of patients with primary and secondary coeliac syndromes responded to a gluten-free diet.

\section{Discussion}

The overall incidence of diarrhoea, loss of weight, and loss of appetite in this group of patients is similar to that reported in other series (Cooke et al., 1953 ; Bossak et al., 1957 ; Green and Wollaeger 1958), although the incidence of abdominal pain and glossitis was lower in our patients.

Comparison of the results obtained in the two groups of patients shows that we were unable to distinguish primary from secondary coeliac syndromes on the basis of any of the investigations regularly per-

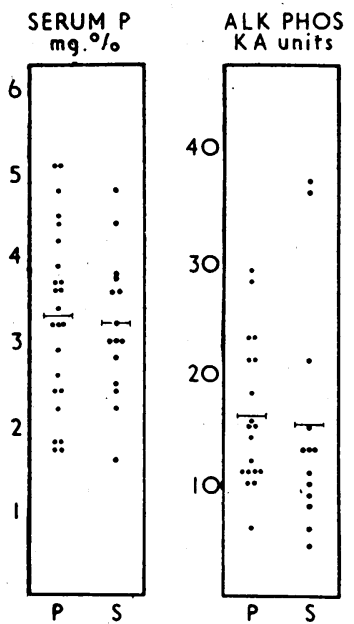
formed in the investigation of such patients. The clinical features in both groups were similar, although abdominal pain was more frequent in patients with a secondary syndrome, as was glossitis in the primary type. None of the haematological, biochemical, or radiological investigations carried out was of any value in separating the two groups, and histologically the biopsy specimens were identical in appearance. Even the response of the two groups to a glutenfree diet was indistinguishable.

In some of the patients with a secondary coeliac syndrome signs or symptoms of the underlying disease were already obvious when they were first seen. However, in other patients only the development of additional signs or further specialized investigations allowed a complete diagnosis to be reached.

\section{Summary}

The clinical and investigative findings in 50 patients with a flat jejunal mucosa are presented. No difference was found between those patients with a primary and those with a secondary coeliac syndrome, and the response to a gluten-free diet was also similar. There seems to be no method of distinguishing the secondary coeliac syndrome from the primary syndrome other than by the recognition of an underlying disease.

\section{REFERENCES}

Bossak, E. T., Wang, C. I., and Adlersberg, D. (1957). F. Mt Sinai Hosp., 24, 286

Cooke, W. T., Peeney, A. L. P., and Hawkins, C. F. (1953). Quart. F. Med., 22, 59.

Green, P. A., and Wollaeger, E. E. (1958). World Congress of Gastro-

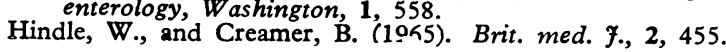

